Canadian

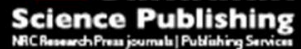

Canadian Journal of Physiology and Pharmacology Revue canadienne de physiologie et pharmacologie

\title{
Sulforaphane improves oxidative status without attenuating the inflammatory response or cardiac impairment induced by ischemia-reperfusion in rats
}

\begin{tabular}{|r|l|}
\hline Journal: & Canadian Journal of Physiology and Pharmacology \\
\hline Manuscript ID & cjpp-2015-0282.R1 \\
\hline Manuscript Type: & Article \\
\hline Date Submitted by the Author: & 07-Oct-2015 \\
\hline & $\begin{array}{l}\text { Bonetto, Jéssica; UFRGS, Physiology } \\
\text { Fernandes, Rafael; UFRGS, Physiology } \\
\text { Seolin, Bruna; UFRGS, Physiology } \\
\text { Müller, Dalvana; UFRGS, Physiology } \\
\text { Teixeira, Rayane; UFRGS, Physiology } \\
\text { Araujo, Alex; UFRGS, Physiology } \\
\text { Vassallo, Dalton; EMESCAM } \\
\text { Schenkel, Paulo; UFRGS, Physiology } \\
\text { Belló-Klein, Adriane; UFRGS, Physiology }\end{array}$ \\
\hline Keyword: & ischemia-reperfusion, sulforaphane, oxidative stress, inflammation, TLR4 \\
\hline
\end{tabular}


Title: Sulforaphane improves oxidative status without attenuating the inflammatory response or cardiac impairment induced by ischemia-reperfusion in rats

Bonetto, Jéssica Hellen Poletto ${ }^{1}$; Fernandes, Rafael Oliveira ${ }^{1}$; Seolin, Bruna Gazzi de Lima ${ }^{1}$; Müller, Dalvana Daneliza ${ }^{1}$; Teixeira, Rayane Brinck ${ }^{1}$; Araujo, Alex Sander ${ }^{1}$; Vassallo, Dalton $^{2}$; Schenkel, Paulo Cavalheiro ${ }^{1}$; Belló-Klein, Adriane ${ }^{1}$

${ }^{1}$ Laboratory of Cardiovascular Physiology, Institute of Basic Health Science (ICBS), Federal University of Rio Grande do Sul (UFRGS), Rio Grande do Sul, Brazil.

${ }^{2}$ Health Science Center of Vitória (EMESCAM), Espírito Santo, Brazil.

\section{Corresponding Author:}

Dr. Adriane Belló-Klein

Mailing address: Laboratório de Fisiologia Cardiovascular, Departamento de Fisiologia, Universidade Federal do Rio Grande do Sul.

Rua Sarmento Leite 500, Porto Alegre/RS, CEP: 90050-170 - Brazil

Phone: 0-55-51-33083621

Fax: 0-55-51-33083656

e-mail: belklein@ufrgs.br 


\begin{abstract}
Sulforaphane, a natural isothiocyanate, demonstrates cardioprotection associated with its capacity to stimulate endogenous antioxidants and to inhibit inflammation. The aim of this study was to investigate if sulforaphane is capable of attenuating oxidative stress and inflammatory responses through the TLR4/MyD88/NFkB pathway, and thereby could modulate post-ischemic ventricular function in isolated rat hearts submitted to ischemia and reperfusion. Male Wistar rats received sulforaphane $(10 \mathrm{mg} / \mathrm{kg} /$ day $)$ or vehicle i.p. for 3 days. Global ischemia was performed using isolated hearts, $24 \mathrm{~h}$ after the last injection, by interruption of the perfusion flow. The protocol included a $20 \mathrm{~min}$ pre-ischemic period followed by $20 \mathrm{~min}$ of ischemia and a $20 \mathrm{~min}$ reperfusion. Although no changes in mechanical function were observed, sulforaphane induced a significant increase in superoxide dismutase and heme oxygenase-1 expression (both 66\%) and significantly reduced reactive oxygen species levels $(7 \%)$. No differences were observed for catalase and glutathione peroxidase expression or their activities, nor for thioredoxin reductase, glutaredoxin reductase and glutathione-S-transferase. No differences were found in lipid peroxidation or TLR4, MyD88 and NF- $\kappa B$ expression. In conclusion, although sulforaphane was able to stimulate endogenous antioxidants modestly, this result did not impact inflammatory signaling or cardiac function of hearts submitted to ischemia and reperfusion.
\end{abstract}

Keywords: ischemia-reperfusion, isolated heart, sulforaphane, oxidative stress, inflammation, TLR4, reactive oxygen species. 


\section{Introduction}

Ischemia and subsequent reperfusion activates a cascade of injurious events associated with increased generation of reactive oxygen species (ROS) (Minamino 2012; Raedschelders et al. 2012). Besides functional impairment (Greensmith et al. 2010), ROS also seem to contribute to injury by activating an immune response in ischemia-reperfusion (Ha et al. 2011). ROS are among the ligands released from ischemic cardiomyocytes, called damageassociated molecular patterns (DAMPs), which interact with pattern recognition receptors (PRR) (Vilahur and Badimon 2014). Among the PRR, Toll-Like Receptors (TLRs), especially TLR2 and TLR4, have been shown to be activated in myocardial ischemiareperfusion by DAMPs (Ha et al. 2011; Vilahur and Badimon 2014).

While the reported role of TLR2 has been controversial, there is agreement regarding the role of TLR4 in ischemia-reperfusion, in that TLR4 deficiency was shown to protect the myocardium against ischemic injury (Vilahur and Badimon 2014). The TLR4-MyD88dependent pathway has MyD88 as the central adaptor molecule that leads to NF-kB activation, resulting in pro-inflammatory cytokine expression (Ha et al. 2011; Vilahur and Badimon 2014).

Although antioxidants have been shown to prevent the translocation and activation of NF-אB (Flohe et al. 1997; Janssen-Heininger 2000), depending on the cell type and intracellular context, ROS have been reported to both activate and repress NF- $\kappa \mathrm{B}$ signaling (Morgan and Liu 2011). This observation, along with the fact that most exogenous antioxidants appear to exert beneficial effects only in experimental studies (Araujo et al. 2006; Ludke et al. 2012) and have not been observed in clinical trials (Ye et al. 2013), highlights the necessity to investigate alternative ways to stimulate endogenous cell defenses.

Sulforaphane (SFN) is a natural isothiocyanate, found in cruciferous vegetables such as broccoli sprouts, which demonstrates the capacity to stimulate the expression of phase II 
and antioxidant enzymes. Regarding the cardiovascular system, a study from our group demonstrated that SFN treatment of $\mathrm{H} 9 \mathrm{c} 2$ cells increased the expression of heme oxygenase$1(\mathrm{HO}-1)$ and the activities of superoxide dismutase (SOD) and catalase (CAT) (Fernandes et al. 2015). In ischemia-reperfusion, treatment of rats with SFN showed an improvement in mechanical function and a preservation of expression of several antioxidants, including CAT, Mn-SOD and HO-1 (Piao et al. 2010).

SFN also has been shown to modulate directly targets related to inflammatory signaling. Regarding the TLR4 pathway, SFN suppressed TLR-4, MyD88, NF-אB translocation and expression of adhesion molecules in cultured vascular endothelial cells (Shan et al. 2012). Another study showed that SFN inhibited the adhesive capacity of cultured mouse vascular smooth muscle cell lines and downregulated the TNF- $\alpha$-mediated induction of VCAM-1, as a result of the suppression of ROS production, the MAPK pathway,

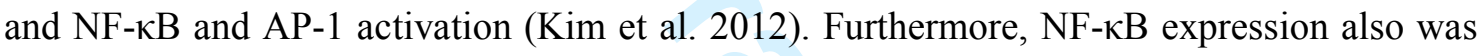
reduced in injured carotid sections from rats treated with SFN (Kwon et al. 2012).

Based on the previously cited studies, it can be seen that there is a paucity of information regarding SFN treatment effects on the cardiovascular system, especially related to pro-inflammatory signaling under ischemia and reperfusion. The aim of this study was to test the hypothesis that SFN pre-treatment could attenuate oxidative stress and the proinflammatory response, and thereby modulate post-ischemic ventricular function in isolated hearts submitted to ischemia-reperfusion.

\section{Materials and Methods}

Animals

Male Wistar rats, weighing 250-300 g, were obtained from the Animal Care Center of the Federal University of Rio Grande do Sul, RS, Brazil. The animals were housed in a 
controlled environment with a $12: 12 \mathrm{~h}$ light-dark cycle at $23{ }^{\circ} \mathrm{C}$ and provided with rat chow (Nuvilab CR-1, Nuvital, São Paulo, Brazil) and water ad libitum. Animal care followed the government guidelines in compliance with the Guide for the Care and Use of Laboratory Animals (1996, published by National Academy Press, 2101 Constitution Ave. NW, Washington, DC, 2055, USA), and was approved by the ethics committee of the Federal University of Rio Grande do Sul, RS, Brazil (protocol number 24771). Animals were randomly divided into the following two groups: control (CTL) and SFN treatment (SFN).

\section{Experimental Protocol}

Administration of SFN or vehicle

Animals from CTL and SFN (R, S-Sulforaphane, LKT Laboratories, St. Paul, USA) groups were treated intraperitoneally, respectively, with vehicle $[0.9 \% \mathrm{w} / \mathrm{v} \mathrm{NaCl}, 0.5 \% \mathrm{w} / \mathrm{v}$ dimethyl sulfoxide (DMSO)] or SFN solubilized in vehicle $(10 \mathrm{mg} / \mathrm{kg} / \mathrm{day})$ to a final administration volume of up to $0.5 \mathrm{~mL}$. The injections were administered for three consecutive days before the isolated heart perfusion. The dose of SFN and treatment protocol were based on a review of several recent studies, which used doses from $0.5 \mathrm{mg} / \mathrm{kg} /$ day to 25 $\mathrm{mg} / \mathrm{kg} /$ day in diverse experimental models, showing no adverse effects (Guerrero-Beltrán et al. 2012; Malaguti et al. 2009; Piao et al. 2010). Based on these studies, an intermediate concentration was selected.

\section{Perfusion Protocol}

Rats were heparinized and sacrificed by decapitation. Hearts were immediately excised, ascending aorta was cannulated, and immediately retrogradely perfused on a Langendorff apparatus (Hugo Sachs Elektronik - Harvard Apparatus, Germany) with a modified Krebs-Henseleit $(\mathrm{K}-\mathrm{H})$ solution (in mmol/L: $120 \mathrm{NaCl} ; 5.4 \mathrm{KCl} ; 1.25 \mathrm{CaCl}_{2} ; 1.8$ 
$\mathrm{MgCl}_{2} ; 27 \mathrm{NaHCO}_{3} ; 2 \mathrm{NaH}_{2} \mathrm{PO}_{4} ; 1.8 \mathrm{Na}_{2} \mathrm{SO}_{4}$ and 11 glucose) maintained at a constant flow of $10 \mathrm{~mL} / \mathrm{min}$ with a peristaltic pump (BP-600.04, Milan, Colombo, Brazil). Perfusate was kept at $37^{\circ} \mathrm{C}$ by a water pump with heater (M3 Lauda, Hugo Sachs Elektronik - Harvard Apparatus, Germany) and was continuously bubbled with $95 \% \mathrm{O}_{2}$ and $5 \% \mathrm{CO}_{2}$, to maintain a $\mathrm{pH}$ of 7.4. To assess contractile function, a latex balloon filled with water and connected to a pressure transducer (TPS-2, São Paulo, Brazil) was inserted into the left ventricular cavity via the left atrium and mitral valve. Left ventricular end-diastolic pressure (LVEDP) was set to approximately $10 \mathrm{mmHg}$ during the stabilization period only, by inflating the balloon with water. Left ventricular diastolic pressure was then continuously recorded, as well as left ventricular systolic pressure (LVSP), contractility index $(+d P / d t)$, relaxation index $(-d P / d t)$, and heart rate (HR). Coronary pressure was detected by another transducer coupled to an aortic cannula. Signals from the transducers were transmitted to a system of data acquisition and analysis (Isoheart, Hugo Sachs Elektronik - Harvard Apparatus, Germany), where data were recorded continuously for later analyses.

Hearts were perfused with Krebs-Henseleit $(\mathrm{KH})$ buffer for a stabilization period of $20 \mathrm{~min}$, then underwent a period of normothermic global ischemia for $20 \mathrm{~min}$, and a period of reperfusion for $20 \mathrm{~min}$. Global ischemia was developed through interruption of the perfusion flow, followed by restoration of the buffer perfusion. These periods were chosen since more than 20 min of ischemia could cause irreversible cardiac dysfunction (Kloner and Jennings 2001; Palmer et al. 2004). To ensure physiologic cardiac functioning, hearts that did not display a heart rate of at least 200 beats/min, and a LVSP or perfusion pressure of at least 60 $\mathrm{mmHg}$ at the end of the stabilization period were excluded.

After finishing the experiments, hearts were quick-frozen in liquid nitrogen and then stored at $-80^{\circ} \mathrm{C}$ for enzymatic and western blotting analysis. 
Tissue preparation for biochemical assays

Hearts were homogenized with $1.15 \% \mathrm{KCl}(\mathrm{w} / \mathrm{v})$ and $20 \mathrm{mmol} / \mathrm{L}$ phenyl methyl sulphonyl fluoride (PMSF) in Ultra-Turrax. The suspension was centrifuged at $3000 \mathrm{rpm}$ for 20 min at $0-4{ }^{\circ} \mathrm{C}$ to remove nuclei and cell debris (Llesuy et al. 1985). The supernatants were used to assay enzymatic activities, determine total ROS levels and evaluate lipid peroxidation.

\section{Determination of antioxidant enzyme activities}

SOD activity was evaluated based on the inhibition of the superoxide radical reaction with pyrogallol, measured at $420 \mathrm{~nm}$. Results were expressed as units/mg of protein (Marklund 1985). CAT activity was measured by following the decrease in hydrogen peroxide $\left(\mathrm{H}_{2} \mathrm{O}_{2}\right)$ absorbance at $240 \mathrm{~nm}$. CAT activity results were expressed as pmol of $\mathrm{H}_{2} \mathrm{O}_{2}$ reduced per min/mg protein (Aebi 1984). Quantification of glutathione peroxidase (GPx) activity is based on the consumption of NADPH and was measured at $340 \mathrm{~nm}$. GPx results were expressed as nmol of peroxide/hydroperoxide reduced per min/mg of protein (Flohe and Gunzler 1984). Measurement of the activity of glutathione S-transferase (GST) is based on the conjugation of dinitrophenol with reduced glutathione. The absorbance of this product was measured at a wavelength of $340 \mathrm{~nm}$. The results were reported in $\mu \mathrm{mol} / \mathrm{mg}$ of protein (Mannervik and Gluthenberg 1981). To evaluate the activity of glutaredoxin (Grx), the protocol established by Holmgren and Áslund (1995) was used. The activity was expressed in $\mathrm{mmol} / \mathrm{mg}$ of protein. Thioredoxin reductase (TrxR) activity was determined from the reduction of the compound 5'5-dithiobis (2-nitrobenzoic acid) (DTNB) to TNB, measured at 412nm. Data were expressed as nmol/min/mg of protein (Holmgren and Björnstedt 1995). 


\section{Determination of total ROS levels}

ROS generation was measured by the $2^{\prime}, 7^{\prime}$-dichlorofluorescin diacetate (DCFH-DA) fluorescence emission method. The assay was performed by incubating cardiac tissue homogenate with a reaction mixture containing DCFH-DA (Sigma Aldrich, St Louis, MO, USA). After 30 minutes of incubation at room temperature, samples were excited at $488 \mathrm{~nm}$ and fluorescence emission of the oxidation product 2,7-dichlorofluorescin (DCF), was assessed with a $525 \mathrm{~nm}$ long pass filter. Data were expressed as $\mathrm{pmol} / \mathrm{mg}$ of protein based on a standard curve performed using DCF (Lebel et al. 1992).

\section{Lipid Peroxidation}

For the TBARS assay, trichloroacetic acid $(10 \%, \mathrm{w} / \mathrm{v})$ was added to the homogenate to precipitate proteins and to acidify the samples. This mixture was then centrifuged $(1000 \times g, 3 \mathrm{~min})$. The protein-free sample was extracted and thiobarbituric acid $(0.67 \%$, $\mathrm{w} / \mathrm{v})$ was added to the reaction medium. Tubes were placed in a water bath $\left(100{ }^{\circ} \mathrm{C}\right)$ for 15 min. When malondialdehyde, the product of lipid peroxidation, is heated in the presence of thiobarbituric acid (TBA), it forms a colored compound which can be measured spectrophotometrically at $532 \mathrm{~nm}$. Results were expressed as $\mu \mathrm{mol} / \mathrm{mg}$ of protein (Buege and Aust 1978).

\section{Western blot analysis}

Cardiac tissue was homogenized (Tris $20 \mathrm{mmol} / \mathrm{L}, \mathrm{NaCl} 150 \mathrm{mmol} / \mathrm{L}$, EDTA 5 $\mathrm{mmol} / \mathrm{L}$, glycerol 10\% w/v, PMSF $20 \mathrm{mmol} / \mathrm{L}$, aprotinin $10 \mu \mathrm{L} / \mathrm{mL}$ and leupeptin $10 \mu \mathrm{L} / \mathrm{mL}$ ) in Ultra-Turrax. The suspension was centrifuged at $1000 \times \mathrm{g}$ for $10 \mathrm{~min}$ at $0-4{ }^{\circ} \mathrm{C}$ to remove nuclei and cell debris. The supernatants were used for the assay. The protein concentration was quantified and used for normalization. Proteins were subject to one-dimensional sodium 
docedyl sulphate-polyacrylamide gel electrophoresis in a discontinuous system using $8-14 \%$ (w/v) stacking and separating gels. The immunodetection steps were processed on PVDF membranes, using the following polyclonal IgG primary antibodies: SOD-1, CAT, GPx, HO1, TLR4, MyD88, NF-кB (Santa Cruz Biotechnology, Santa Cruz, USA; Cell Signaling Technology, Beverly, USA). The bound primary antibodies were detected with anti-rabbit or anti-mouse horseradish peroxidase-conjugated secondary antibodies. Membranes were developed using a chemiluminescent reagent. ECL hyper films were resolved in a manual system prepared using a Kodak radiographic revelator and fixator, prepared as per the manufacturer's instructions. The loading controls were GAPDH or $\alpha$-actinin. The generated autoradiographs were quantitatively measured with an image densitometer (Imagemaster VDS CI, Amersham Biosciences Europe, IT). Data were expressed as units of optical density quantified by the software Image J 1.47t (National Institute of Health, Bethesda, USA,) and normalized to the protein loading control (Klein 1995; Laemmli 1970).

\section{Determination of protein concentration}

Protein was measured by the method of Lowry et al. (1951), with bovine serum albumin as the standard.

\section{Statistical analysis}

Parametric data were expressed as mean \pm S.D. and compared using the unpaired Student's $t$-test. When the data had non-parametric distribution, the differences were checked by the Mann-Whitney test and were expressed as median and interquartile range. Sigma Plot Software (Version 12.0, Systat Software Inc., San Jose, USA) was used to test the differences. Values of $P<0.05$ were considered significant. 


\section{Results}

Mechanical function

At the end of the stabilization period, both groups had similar basal cardiovascular function. All measured parameters, such as LVSP, LVEDP, $\pm \mathrm{dP} / \mathrm{dt}$, perfusion pressure and heart rate, were comparable between groups (Table 1). At the end of the reperfusion period, no significant differences were observed in any of the measured parameters (Table 2). The same was visualized during initial periods of reperfusion (data not shown). A typical recording of the entire perfusion protocol is showed in Figure 1. The characteristic phenomena of ischemia (ischemic contracture), and reperfusion (hypercontracture and myocardial stunning) can be observed.

\section{Oxidative stress parameters}

To determine the role of SFN on the cellular antioxidant system, antioxidant enzyme expression and activity were analyzed. SFN increased the expression of CuZn-SOD $(66 \%$, Fig. 2A) and HO-1 (66\%, Fig. 8) when compared with the control group. No differences in the expression of CAT (Fig. 3A) and GPx (Fig. 4A) were observed after reperfusion in ventricular tissue of rats treated with SFN when compared with the control. .

Regarding the activity of antioxidant enzymes, total SOD activity, comprised of CuZn-SOD and Mn-SOD, was not different between groups (Fig. 2B). Antioxidant enzymes that catalyze the reduction of $\mathrm{H}_{2} \mathrm{O}_{2}$, such as CAT, GPx, GrxR and TrxR (Figs. 3B, 4B, 5 and 6) were not significantly different between SFN and vehicle treated rats.

GST, an important phase II enzyme able to biotransform SFN by conjugation with GSH, did not show activity differences after ischemia and reperfusion in cardiac tissue of rats with or without SFN treatment (Fig. 7). 
Finally, SFN significantly reduced ROS levels (7\%) when compared with control (Fig. 9), but did not reduce lipid peroxidation as assessed by the TBARS method (Fig. 10).

\section{Inflammatory parameters}

To investigate the role of SFN on the inflammatory response triggered by TLR4 activation under ischemia and reperfusion, the protein expression level for three components of the TLR4 pathway, TLR4, MyD88 and NF- $\kappa$ B, was determined. SFN did not suppress TLR4 or MyD88 expression (Fig. 11 and 12) following this treatment regimen. Also, NF- $\kappa B$, a transcription factor that stimulates the expression of pro-inflammatory cytokines, was not significantly different when compared with the control group (Fig. 13), even with the significant decrease in total ROS production.

\section{Discussion}

To the best of our knowledge, the present study is the first to report SFN modulation of the TLR4/MyD88/NF- $\mathrm{B}$ pathway activated by ischemia-reperfusion in an isolated heart model. With the treatment regimen used, SFN was capable of modifying the intracellular oxidative status, increasing the expression of antioxidant enzymes, such as SOD-1 and HO-1, and reducing total ROS levels in isolated hearts submitted to ischemia and reperfusion. Despite these actions, SFN was unable to inhibit the immune response mediated through the TLR4/MyD88/NF- $\mathrm{B}$ pathway, neither directly nor as a consequence of the decrease in ROS levels. In parallel, SFN was not able to attenuate the functional impairment resulting from ischemia and reperfusion.

SFN has been studied since the 1980 s due to its anti-cancer properties, especially antiproliferative and anti-angiogenic properties. Recently, research has focused on its effects in different organs such as the brain, kidney and liver, and different pathological conditions 
such as diabetes (Guerrero-Beltrán et al. 2012). There are still only limited studies exploring SFN treatment in cardiovascular disease. Regarding ischemia-reperfusion, a study in 2010 verified that this compound $(0.5 \mathrm{mg} / \mathrm{kg} /$ day i.p. for three days $)$ was able to inhibit the post ischemic LVEDP increase, in addition to increasing developed pressure (DP), contractility index, and coronary flow (Piao et al. 2010). In contrast, it was not observed improvement of the functional impairment in the present study with the established protocol.

Mukherjee et al. (2008) showed similar results to Piao et al. (2010) regarding post ischemic ventricular function. It is worth noting that in the Mukherjee study, rats received daily broccoli extract orally over a period of 30 days before their hearts were submitted to the ischemia and reperfusion protocol. Ischemia and reperfusion periods also were longer in both studies than in ours.

Periods of ischemia longer than 20 minutes cause irreversible changes in myocardium (Kloner and Jennings 2001). In this study, 20 minutes of ischemia caused functional impairment evidenced mainly by the increase of LVEDP as a result of ischemic contracture, developed during the last five minutes of ischemia (Fig. 1). Ischemic contracture is related to the strong interaction between actin and myosin chains due to the great depletion of ATP in ischemia (Cokkinos et al. 2006). Early reperfusion also generated a hypercontracted state (Fig. 1), which is suggested to result from the calcium overload due to reversed activity of the $\mathrm{Na}^{+} / \mathrm{Ca}^{++}$exchanger (Cokkinos et al. 2006). Finally, another phenomenon that occurs after ischemia and was observed in this study, is the "stunning myocardium", which has been associated to calcium overload and ROS overproduction (Bianchini and Belló 1988; Cokkinos et al. 2006; Kloner and Jennings 2001).

Recent studies have demonstrated that the chemoprotective role of SFN is mainly associated with its pro-apoptotic action at high doses (Chen et al. 2013; Sakao and Singh 2012; Suppipat et al. 2012). On the other hand, the cardioprotective action of SFN is related 
to its capacity to induce phase II and antioxidant enzymes in low doses (Piao et al. 2010). Therefore, SFN does not act as an antioxidant per se, but by stimulating intracellular machinery to increase its own endogenous antioxidant reserve (Dinkova-Kostova and Talalay 2008; Guerrero-Beltrán et al. 2012).

It is well established that SFN is capable of inducing expression and increasing activity of antioxidant defenses, such as SOD, CAT and GPx (Zhu et al. 2008). A study from our group corroborates this evidence, since cardiac myoblasts treated with SFN showed increased SOD, CAT and GST activity (Fernandes et al. 2015). In the present study, there was a significantly higher expression (66\%) of CuZn-SOD in treated hearts as compared with control.

Although SFN stimulated increased expression of CuZn-SOD, there was no increase on total SOD activity when the SFN group was compared with control. The unchanged total activity could be influenced by a decrease of Mn-SOD activity. This statement is based on the important role of SOD on ischemia-reperfusion injury, evidenced mainly by its deficiency or overexpression in this model (Marczin et al. 2003; Rodrigo et al. 2013). This hypothesis should be tested to make this assumption.

Regarding the expression of CAT and GPx, there were no significant differences between groups. The same results were observed for the activities of these and other antioxidant enzymes, such as GrxR and TrxR. In a study of rat skeletal muscle submitted to exhaustive exercise, treatment with SFN was not capable of increasing expression and activity of GPx. The same was observed with TrxR (Malaguti et al. 2009). It is important to highlight that in their study, animals were pretreated with SFN at a dose of $25 \mathrm{mg} / \mathrm{kg}$ body weight (i.p.).

Several studies have shown the capacity of SFN to induce both expression and activity of GST (Morimistu et al. 2002; Riedl et al. 2009). In the present study there was no 
difference in total GST activity in rat hearts treated with $10 \mathrm{mg} / \mathrm{kg} /$ day of SFN and submitted to ischemia-reperfusion. There are seven isoforms of cytosolic GSTs, but only three of them have been implicated in isothiocyanate metabolism (GSTM1, GSTP1 and GSTT1) (Boddupalli 2012). Since in this study total GST activity was determined, the effect of SFN over a particular isoform could be partially masked by the activity of the other isoforms (Juge et al. 2007).

The action of SFN as an inducer of HO-1 is well-recognized, since several studies have demonstrated the increase of its expression in cultured cardiac cells (Fernandes et al. 2015), human upper airway cells (Riedl et al. 2009), animal cardiac tissue (Bai et al. 2013), and especially in regard to ischemia and reperfusion in several organs (Mukherjee et al. 2008; Piao et al. 2010; Ping et al. 2010; Yoon et al. 2008; Zhao et al. 2010). In the present study, when HO-1 was assessed, it was observed that SFN increased the expression of this protein by $66 \%$. HO-1 acts by degrading heme groups into carbon monoxide $(\mathrm{CO})$, bilirubin (from biliverdin) and iron. These biomolecules act on ischemia-reperfusion injury, by attenuating oxidative stress, inflammation and apoptosis $(\mathrm{Wu}, 2011)$. Once there is a regulatory pattern, the induction of $\mathrm{HO}-1$ is considered an adaptive response to oxidative stress and a protective mechanism for different stimuli (Barbagallo et al. 2013). Thus, SFN induction of this stressresponsive enzyme, for instance, could be considered an important therapeutic strategy against oxidative stress and inflammatory processes.

Ischemia followed by reperfusion starts a cascade of injurious events related to ROS overproduction. Generation of ROS is proportional to the period of ischemia, since longer periods increase the damage to the mitochondrial electron transporter (Raedschelders et al. 2012). In the present study, ROS levels were significantly lower in the SFN group than in control, possibly related to increased expression of HO-1. 
Several studies have shown the ability of SFN to significantly reduce lipid peroxidation (Malaguti et al. 2009; Ping et al. 2010; Yoon et al. 2008). The present study did not show significant differences in lipid peroxidation as assessed by the TBARS assay. It is interesting to note that there was no difference in this marker even with the reduction of total ROS levels in the SFN group, possibly because it was a small reduction (7\%). Moreover, no observed modification of lipid peroxidation suggests that there was no difference in lipid hydroperoxide formation. This finding is consistent with the lack of change for GPx activity, since this enzyme acts by metabolizing these lipid peroxidation products (Trachootham et al. 2008).

Recent evidence has suggested that ischemic cardiomyocytes can be a significant source of innate immune responses (Lin and Knowlton 2014). The release of multiple DAMPs, including ROS, from stressed cardiomyocytes, activates the immune response through TLR4/MyD88/NF-אB, leading to inflammatory signaling and cytokine expression (Ha et al. 2011; Lin and Knowlton 2014). This is the first study investigating the role of SFN on this pathway in cardiac ischemia-reperfusion. Since SFN induced only a slight reduction on ROS levels in this study, it was not able to modulate significantly this pathway. SFN also has been shown to directly inhibit NF- $\mathrm{B}$ activity through different mechanisms, including inhibiting the activation by affecting oligomerization of TLR4, suppressing expression of downstream effectors, and reducing nuclear translocation of $\mathrm{NF}-\kappa \mathrm{B}$, among other mechanisms (Shan et al. 2012; Wu et al. 2004; Youn et al. 2010). In order to explore these mechanisms, other evaluation methods, such as nuclear translocation, would be necessary to obtain consistent conclusions.

In summary, pre-treatment with $10 \mathrm{mg} / \mathrm{kg} /$ day of SFN was capable of stimulating the expression of important endogenous antioxidants, such as HO-1 and SOD in isolated rat hearts submitted to ischemia and reperfusion. Moreover, even without modification of 
enzymatic activities, SFN decreased ROS levels, which did not influence the cardiac TLR4 pathway since it was a slight ROS reduction. The observed changes did not reflect on postischemic ventricular function of hearts submitted to ischemia-reperfusion. More studies with different treatment protocols are necessary to completely elucidate these remaining issues.

\section{Acknowledgments}

This work was supported by the Brazilian Research Agencies, Conselho Nacional de Desenvolvimento Científico e Tecnológico (CNPq), Coordenação de Aperfeiçoamento de Pessoal de Nível Superior (CAPES) and Fundação de Amparo à Pesquisa do Rio Grande do Sul (FAPERGS).

\section{Conflict of interest}

The authors declare that there is no conflict of interest that could be perceived as prejudicing the impartiality of the research report.

\section{References}

Aebi, H. 1984. Catalase in vitro. Methods Enzymol. 105: 121-126.

Araujo, A.S., Ribeiro, M.F., Enzveiler, A., Schenkel, P., Fernandes, T.R., Partata, W.A., et al. 2006. Myocardial antioxidant enzyme activities and concentration and glutathione metabolism in experimental hyperthyroidism. Mol. Cell. Endocrinol. 249(1-2): 133-139.

Bai, Y., Cui, W., Xin, Y., Miao, X., Barati, M.T., Zhang, C., et al. 2013. Prevention by sulforaphane of diabetic cardiomyopathy is associated with up-regulation of Nrf2 expression 
and transcription activation. J. Mol. Cell. Cardiol. 57: 82-95. doi:

10.1016/j.yjmcc.2013.01.008

Barbagallo, I., Galvano, F., Frigiola, A., Cappello, F., Riccioni, G., Murabito, P., et al. 2013. Potential Therapeutic Effects of Natural Heme Oxygenase-1 Inducers in Cardiovascular Diseases. Antioxid. Redox. Signal. 18(5): 507-21. doi: 10.1089/ars.2011.4360

Bianchini, A., and Belló, A.A. 1988. Hydrogen peroxide effects on the contractile force and the coronary flow of the rat isolated heart. Med. Sci. Res. 16: 1265-1266.

Boddupalli, S., Mein, J.R., Lakkanna, S., and James, D.R. 2012. Induction of phase 2 antioxidant enzymes by broccoli sulforaphane: perspectives in maintaining the antioxidant activity of vitamins A, C, and E. Front. Genet. 3: 7. doi: 10.3389/fgene.2012.00007

Buege, J.A., and Aust, S.D. 1978. Microsomal lipid peroxidation. Methods Enzymol. 52: $302-10$.

Chen, H., Landen, C.N., Li, Y., Alvarez, R.D., and Tollefsbol, T.O. 2013. Epigallocatechin Gallate and Sulforaphane Combination Treatment Induce Apoptosis in Paclitaxel-Resistant Ovarian Cancer Cells through hTERT and Bcl-2 Down-regulation. Exp. Cell. Res. 319(5): 697-706. doi: 10.1016/j.yexcr.2012.12.026

Cokkinos, D.V., Pantos, C., Heusch, G., and Taegtmeyer, H. 2006. Myocardial Ischemia Basic Concepts. In Myocardial Ischemia - From Mechanisms to Therapeutic Potentials. Edited by D.V. Cokkinos, C. Pantos, G. Heusch, and H. Taegtmeyer. Springer Press, New York, pp. 20-26. 
Dinkova-Kostova, A.T., and Talalay, P. 2008. Direct and indirect antioxidant properties of inducers of cytoprotective proteins. Mol. Nutr. Food Res. 52: S128-S138. doi:

10.1002/mnfr.200700195

Fernandes, R.O., Bonetto, J.H.P., Baregzay, B., de Castro, A.L., Puukila, S., Forsyth, H., et al. 2015. Modulation of apoptosis by sulforaphane is associated with PGC-1a stimulation and decreased oxidative stress in cardiac myoblasts. Mol. Cell. Biochem. 401(1-2): 61-70. doi: $10.1007 / \mathrm{s} 11010-014-2292-\mathrm{Z}$

Flohe, L., Brigelius-Flohe, R., Saliou, C., Traber, M.G., and Packer, L. 1997. Redox regulation of NF-kB activation. Free Radic. Biol. Med. 22(6): 1115-1126.

Flohé, L., and Gunzler, W.A. 1984. Assays of Glutathione Peroxidase. Methods Enzymol. 105: $114-121$.

Greensmith, D.J., Eisnera, D.A., and Nirmalan, M. 2010. The effects of hydrogen peroxide on intracellular calcium handling and contractility in the rat ventricular myocyte. Cell

Calcium, 48(6): 341-351. doi: 10.1016/j.ceca.2010.10.007

Guerrero-Beltrán, C.E., Calderón-Oliver, M., Pedraza-Chaverri, J., and Chirino, Y.I. 2012. Protective effect of sulforaphane against oxidative stress: Recent advances. Exp. Toxicol. Pathol. 64(5): 503-508. doi: 10.1016/j.etp.2010.11.005

Ha, T., Liu, L., Kelley, J., Kao, R., Williams, D., and Li, C. 2011. Toll-like Receptors: New Players in Myocardial Ischemia/Reperfusion Injury. Antioxid. Redox. Signal. 15(7): 187593. doi: 10.1089/ars.2010.3723

Holmgren, A., and Åslund, F. 1995. Glutaredoxin. Methods Enzymol. 252: 283-292 
Holmgren, A., and Björnstedt, M. 1995. Thioredoxin and thioredoxin reductase. Methods Enzymol. 252: 199-208.

Janssen-Heininger, Y.M., Poynter, M.E., and Baeuerle, P.A. 2000. Recent advances towards understanding redox mechanisms in the activation of nuclear factor kB. Free Radic. Biol.

Med. 28(9): 1317-1327.

Juge, N., Mithen, R.F., and Traka, M. 2007. Molecular basis for chemoprevention by sulforaphane: a comprehensive review. Cell. Mol. Life Sci. 64(9): 1105-1127. doi: $10.1007 / \mathrm{s} 00018-007-6484-5$

Kim, Y.M., Pae, H.O., Park, J.E., Lee, Y.C., Woo, J.M., Kim, N.H., et al. 2012. Heme Oxygenase in the Regulation of Vascular Biology: From Molecular Mechanisms to Therapeutic Opportunities. Antioxid. Redox. Signal. 14(1): 137-67. doi: $10.1089 /$ ars. 2010.3153

Klein, D., Kern, R.M., and Sokol, R.Z. 1995. A method for quantification and correction of proteins after transfer to immobilization membranes. Biochem. Mol. Biol. 36(1): 59-66.

Kloner, R.A., and Jennings, R.B. 2001. Consequences of Brief Ischemia: Stunning, Preconditioning, and Their Clinical Implications. Circulation, 104(24): 2981-2989.

Kwon, J.S., Joung, H., Kim, Y.S., Shim, Y.S., Ahn, Y., Jeong, M.H., et al. 2012. Sulforaphane inhibits restenosis by suppressing inflammation and the proliferation of vascular smooth muscle cells. Atherosclerosis, 225(1): 41-49. doi:

10.1016/j.atherosclerosis.2012.07.040

Laemmli, V. 1970. Cleavage of structural proteins during the assembly of the head of bacteriophage T4. Nature, 227(5259): 680-685. 
Lebel, C.P., Ischiropoulos, H., and Bondy, S.C. 1992. Evaluation of the probe 2',7'-

dichlorofluorescin as an indicator of reactive oxygen species formation and oxidative stress.

Chem. Res. Toxicol. 5(2): 227-31.

Lin, L., and Knowlton, A.A. 2014. Innate immunity and cardiomyocytes in ischemic heart disease. Life Sci. 100(1):1-8. doi: 10.1016/j.1fs.2014.01.062

Llesuy, S.F., Milei, J., Molina, H., Boveris, A., and Milei, S. 1985. Comparison of lipid peroxidation and myocardial damage induced by adriamycin and 4'-epiadriamycin in mice. Tumori. 71(3): 241-249.

Lowry, O.H., Rosebrough, N.J., Farr, A.L., and Randall, R.J. 1951. Protein measurement with the folin phenol reagent. J. Biol. Chem. 193(1): 265-275.

Ludke, A.R., Sharma, A.K., Akolkar, G., Bajpai, G., and Singal, P.K. 2012. Downregulation of vitamin C transporter SVCT-2 in doxorubicin-induced cardiomyocyte injury. Am. J.

Physiol. 303(6): C645-5. doi: 10.1152/ajpcell.00186.2012

Malaguti, M., Angeloni, C., Garatachea, N., Baldini, M., Leoncini, E., Collado, P.S., et al. 2009. Sulforaphane treatment protects skeletal muscle against damage induced by exhaustive exercise in rats. J. Appl. Physiol. 107(4): 1028-1036. doi: 10.1152/japplphysiol.00293.2009

Mannervik, B., and Gluthenberg, C. 1981. Glutathione Transferase. Methods Enzymol. 77: $231-235$.

Marczin, N., El-Habashi, N., Hoare, G.S., Bundy, R.E., and Yacoub, M. 2003. Antioxidants in myocardial ischemia-reperfusion injury: therapeutic potential and basic mechanisms. Arch. Biochem. Biophys. 420(2): 222-236. 
Marklund, S. 1985. Pyrogallol autooxidation. In Handbook of methods for oxygen radical research. Edited by R.A. Greenwald. CRC Press, Boca Raton; pp. 243 - 247.

Minamino, T. 2012. Cardioprotection from ischemia/reperfusion injury - Basic and Translational Research. Circ. J. 76(5): 1074-1082.

Morgan, M.J., and Liu, Z.G. 2011. Crosstalk of reactive oxygen species and NF-кB signaling. Cell. Res. 21(1): 103-115. doi: 10.1038/cr.2010.178

Morimitsu, Y., Nakagawa, Y., Hayashi, K., Fujii, H., Kumagai, T., Nakamura, Y., et al. 2002. A sulforaphane analogue that potently activates the nrf2-dependent detoxification pathway. J.Biol.Chem. 277(5): 3456-3463.

Mukherjee, S., Gangopadhyay, H., and Das, D.K. 2008. Broccoli: a unique vegetable that protects mammalian hearts through the redox cycling of the thioredoxin superfamily. J. Agric. Food Chem. 56(2): 609-617. doi: 10.1021/jf0728146

Palmer, B.S., Hadziahmetovic, M., Veci, T., and Angelos, M.G. 2004. Global ischemic duration and reperfusion function in the isolated perfused rat heart. Resuscitation, 62(1): 97106.

Piao, C.S., Gao, S., Lee, G.H., Kim, do S., Park, B.H., Chae, S.W., et al. 2010. Sulforaphane protects ischemic injury of hearts through antioxidant pathway and mitochondrial KATP channels. Pharmacol. Res. 61(4): 342-348. doi: 10.1016/j.phrs.2009.11.009

Ping, Z., Liu, W., Kang, Z., Cai, J., Wang, Q., Cheng, N., et al. 2010. Sulforaphane protects brains against hypoxic-ischemic injury through induction of Nrf2-dependent phase 2 enzyme. Brain Res. 1343: 178-185. doi: 10.1016/j.brainres.2010.04.036 
Raedschelders, K., Ansley, D.M., and Chen, D.D.Y. 2012. The cellular and molecular origin of reactive oxygen species generation during myocardial ischemia and reperfusion.

Pharmacol. Ther. 133(2): 230-255. doi: 10.1016/j.pharmthera.2011.11.004

Riedl, M., Saxon, A., and Diaz-Sanchez, D. 2009. Oral sulforaphane increases Phase II antioxidant enzymes in the human upper airway. Clin. Immunol. 130(3): 244-251. doi: 10.1016/j.clim.2008.10.007

Rodrigo, R., Prieto, J.C., and Castillo, R. 2013. Cardioprotection against ischaemia/reperfusion by vitamins $\mathrm{C}$ and $\mathrm{E}$ plus n-3 fatty acids: molecular mechanisms and potential clinical applications. Clin. Sci. 124(1): 1-15. doi: 10.1042/CS20110663

Sakao, K., and Singh, S.V. 2012. D,L-Sulforaphane-induced apoptosis in human breast cancer cells is regulated by the adapter protein $\mathrm{p} 66^{\text {Shc }}$. J. Cell Biochem. 113(2): 599-610. doi: $10.1002 /$ jcb. 23386

Shan, Y., Lin, N., Yang, X., Tan, J., Zhao, R., Dong, S., et al. 2012. Sulphoraphane inhibited the expressions of intercellular adhesion molecule-1 and vascular cell adhesion molecule-1 through MyD88-dependent toll-like receptor-4 pathway in cultured endothelial cells. Nutr. Metab. Cardiovasc. Dis. 22(3): 215-222. doi: 10.1016/j.numecd.2010.06.013

Suppipat, K., Park, C.S., Shen, Y., Zhu, X., and Lacorazza, H.D. 2012. Sulforaphane induces cell cycle arrest and apoptosis in acute lymphoblastic leukemia cells. PLoS One, 7(12): e51251. doi: 10.1371/journal.pone.0051251

Trachootham, D., Lu, W., Ogasawara, M.A., Nilsa, R.D., and Huang, P. 2008. Redox regulation of cell survival. Antioxid. Redox. Signal. 10(8): 1343-74. doi:

10.1089/ars.2007.1957 
Vilahur, G., and Badimon, L. 2014. Ischemia/reperfusion activates myocardial innate immune response: the key role of the toll-like receptor. Front. Physiol. 18: 5-496. doi: 10.3389/fphys.2014.00496

Wu, L., Noyan Ashraf, M.H., Facci, M., Wang, R., Paterson, P.G., Ferrie, A., et al. 2004. Dietary approach to attenuate oxidative stress, hypertension, and inflammation in the cardiovascular system. Proc. Natl. Acad. Sci. U.S.a. 101(18): 7094-9.

Wu, M.L., Ho, Y., and Yet, S.F. 2011. A central role of heme oxygenase-1 in cardiovascular protection. Antioxid. Redox. Signal. 15(7): 1835-46. doi: 10.1089/ars.2010.3726

Ye, Y., Li, J., and Yuan, Z. 2013. Effect of antioxidant vitamin supplementation on cardiovascular outcomes: a meta-analysis of randomized controlled trials. PLoS One, 8(2): e56803. doi: 10.1371/journal.pone.0056803

Yoon, H., Kang, N., Lee, H., Jang, K.Y., Park, J.W., and Park, B.H. 2008. Sulforaphane protects kidneys against ischemia-reperfusion injury through induction of the Nrf2-dependent phase 2. Biochem. Pharmacol. 75(11): 2214-2223. doi: 10.1016/j.bcp.2008.02.029

Youn, H.S., Kim, Y.S., Park, Z.Y., Kim, S.Y., Choi, N.Y., Joung, S.M., et al. Sulforaphane suppresses oligomerization of TLR4 in a thiol-dependent manner. J. Immunol. 184(1): 411419. doi: 10.4049/jimmunol.0803988

Zhao, H.D., Zhang, F., Shen, G., Li, Y.B., Li, Y.H., Jing, H.R., et al. 2010. Sulforaphane protects liver injury induced by intestinal ischemia reperfusion through Nrf2-ARE pathway. World J. Gastroenterol. 16(24): 3002-10.

Zhu, H., Jia, Z., Strobl, J.S., Ehrich, M., Misra, H.P., and Li, Y. 2008. Potent induction of total cellular and mitochondrial antioxidants and phase 2 enzymes by cruciferous 
sulforaphane in rat aortic smooth muscle cells: cytoprotection against oxidative and electrophilic stress. Cardiovasc. Toxicol. 8(3): 115-125. doi: 10.1007/s12012-008-9020-4 
Table 1. Final period of stabilization. Heart rate (HR), left ventricular systolic pressure (LVSP), left ventricular end diastolic pressure (LVEDP), contractility index $(+d P / d t)$, relaxation index $(-\mathrm{dP} / \mathrm{dt})$ and coronary perfusion pressure (PP) across the different experimental groups.

\begin{tabular}{ccccccc}
\hline & HR & LVSP & LVEDP & $+\mathbf{d P} / \mathbf{d t}$ & $\mathbf{- d P / d t}$ & $\mathbf{P P}$ \\
Groups & $\mathbf{( b p m )}$ & $\mathbf{( m m H g )}$ & $\mathbf{( m m H g )}$ & $\mathbf{( m m H g / s})$ & $\mathbf{( m m H g / s})$ & $\mathbf{( m m H g )}$ \\
\hline CTL & $239 \pm 18$ & $79 \pm 12$ & $10 \pm 2$ & $2061 \pm 675$ & $1717 \pm 592$ & $77 \pm 10$ \\
SFN & $239 \pm 16$ & $85 \pm 13$ & $9 \pm 1$ & $1951 \pm 215$ & $1594 \pm 134$ & $75 \pm 11$ \\
\hline
\end{tabular}

Values represent mean \pm S.D. of 12 animals per group. CTL - vehicle treated rats; SFN sulforaphane treated rats $(10 \mathrm{mg} / \mathrm{kg} /$ day $)$.

Table 2. Final period of reperfusion. Heart rate (HR), left ventricular systolic pressure (LVSP), left ventricular end diastolic pressure (LVEDP), contractility index $(+\mathrm{dP} / \mathrm{dt})$, relaxation index $(-\mathrm{dP} / \mathrm{dt})$ and coronary perfusion pressure (PP) across the different experimental groups.

\begin{tabular}{ccccccc}
\hline & HR & LVSP & LVEDP & $+\mathbf{d P} / \mathbf{d t}$ & $\mathbf{- d P / d t}$ & PP \\
Groups & $\mathbf{( b p m )}$ & $\mathbf{( m m H g )}$ & $\mathbf{( m m H g )}$ & $\mathbf{( m m H g / s})$ & $\mathbf{( m m H g / s})$ & $\mathbf{( m m H g )}$ \\
\hline CTL & $215 \pm 17$ & $99 \pm 15$ & $34 \pm 19$ & $2105 \pm 1493$ & $1690 \pm 922$ & $78 \pm 8$ \\
SFN & $207 \pm 23$ & $93 \pm 9$ & $37 \pm 15$ & $1860 \pm 773$ & $1780 \pm 902$ & $82 \pm 11$ \\
\hline
\end{tabular}

Values represent mean \pm S.D. of 12 animals per group. CTL - vehicle treated rats; SFN sulforaphane treated rats $(10 \mathrm{mg} / \mathrm{kg} /$ day $)$. 


\section{Figure captions}

Figure 1. A typical recording from this study showing the characteristic phenomena of ischemic contracture (full smaller black arrow), hypercontracture (dotted black arrow) and myocardial stunning (larger black arrow). Events assessed by ventricular pressure fluctuations throughout the perfusion protocol with the isolated heart.

Figure 2. Immunocontent of $\mathrm{Cu}-\mathrm{Zn}$ Superoxide Dismutase (SOD) (A) and total SOD activity (B) in homogenates of isolated rat hearts submitted to ischemia and reperfusion after treatment with sulforaphane or vehicle for 3 days. Results are expressed as mean \pm S.D. Western blot analysis: 4-5 animals per group (one representative Western blot experiment showing 3 bands for each experimental group); GAPDH was used for normalization. Enzymatic activity assay: 11-12 animals per group. Comparisons between groups were made using the Student's $t$-test. * Significant difference vs. CTL, $P=0.01$ (A); $P=0.96$ (B). CTL vehicle treated rats; SFN - sulforaphane treated rats $(10 \mathrm{mg} / \mathrm{kg} /$ day for 3 days $)$.

Figure 3. Immunocontent (A) and activity (B) of catalase (CAT) in homogenates of isolated rat hearts submitted to ischemia and reperfusion after treatment with sulforaphane or vehicle for 3 days. Results are expressed as mean \pm S.D. Western blot analysis: 4-5 animals per group (one representative Western blot experiment showing 3 bands for each experimental group); GAPDH was used for normalization. Enzymatic activity assay: 11-13 animals per group. Comparisons between groups were made using the Student's $t$-test. $P=0.58$ (A); $P=$ 0.52 (B). CTL - vehicle treated rats; SFN - sulforaphane treated rats $(10 \mathrm{mg} / \mathrm{kg} / \mathrm{day}$ for 3 days). 
Figure 4. Immunocontent (A) and activity (B) of glutathione peroxidase (GPx) in homogenates of isolated rat hearts submitted to ischemia and reperfusion after treatment with sulforaphane or vehicle for 3 days. Results are expressed as mean \pm S.D. Western blot analysis: 4-5 animals per group (one representative Western blot experiment showing 3 bands for each experimental group); GAPDH was used for normalization. Enzymatic activity assay: 11-12 animals per group. Comparisons between groups were made using the Student's $t$-test. $P=0.19(\mathrm{~A}) ; P=0.75(\mathrm{~B})$. CTL - vehicle treated rats; SFN - sulforaphane treated rats (10 $\mathrm{mg} / \mathrm{kg} /$ day for 3 days).

Figure 5. Glutaredoxin (Grx) activity in homogenates of isolated rat hearts submitted to ischemia and reperfusion after treatment with sulforaphane or vehicle for 3 days. Results are expressed as mean \pm S.D. with 10-12 animals per group. Comparisons between groups were made using the Student's $t$-test. $P=0.84$. CTL - vehicle treated rats; SFN - sulforaphane treated rats $(10 \mathrm{mg} / \mathrm{kg} /$ day for 3 days $)$.

Figure 6. Thioredoxin Reductase (TrxR) activity in homogenates of isolated rat hearts submitted to ischemia and reperfusion after treatment with sulforaphane or vehicle for 3 days. Results are expressed as mean \pm S.D. with 8-10 animals per group. Comparisons between groups were made using the Student's $t$-test. $P=0.75$. CTL - vehicle treated rats; SFN sulforaphane treated rats $(10 \mathrm{mg} / \mathrm{kg} /$ day for 3 days $)$.

Figure 7. Glutathione S-transferase (GST) activity in homogenates of isolated rat hearts submitted to ischemia and reperfusion after treatment with sulforaphane or vehicle for 3 days. Results are expressed as mean \pm S.D. with 7-9 animals per group. Comparisons between groups were made using the Student's $t$-test. $P=0.25$. CTL - vehicle treated rats; SFN sulforaphane treated rats $(10 \mathrm{mg} / \mathrm{kg} /$ day for 3 days $)$. 
Figure 8. Immunocontent of heme oxygenase-1 (HO-1) in homogenates of isolated rat hearts submitted to ischemia and reperfusion after treatment with sulforaphane or vehicle for 3 days. GAPDH was used for normalization. Results are expressed as mean \pm S.D. with 4-5 animals per group (one representative Western blot experiment showing 3 bands for each experimental group). Comparisons between groups were made using the Student's $t$-test. * Significant difference vs. CTL, $P=0.007$. CTL - vehicle treated rats; SFN - sulforaphane treated rats $(10 \mathrm{mg} / \mathrm{kg} / \mathrm{day}$ for 3 days $)$.

Figure 9. Determination of total ROS levels by $2^{\prime}, 7^{\prime}$-dichlorofluorescin diacetate (DCFH-DA) fluorescence emission in homogenates of isolated rat hearts submitted to ischemia and reperfusion after treatment with sulforaphane or vehicle for 3 days. Results are expressed as mean \pm S.D. with 11-12 animals per group. Comparisons between groups were made using the Student's $t$-test. * Significant difference vs. CTL, $P=0.02$. CTL - vehicle treated rats; SFN - sulforaphane treated rats $(10 \mathrm{mg} / \mathrm{kg} /$ day for 3 days $)$.

Figure 10. Lipid peroxidation measured by determination of TBARS in homogenates of isolated rat hearts submitted to ischemia and reperfusion after treatment with sulforaphane or vehicle for 3 days. Results are expressed as the median $\left(\mathrm{P}_{25}, \mathrm{P}_{75}\right)$ with 11 animals per group. Comparisons between groups were made using the Mann-Whitney's $U$ test. $P=0.23$. CTL vehicle treated rats; SFN - sulforaphane treated rats $(10 \mathrm{mg} / \mathrm{kg} /$ day for 3 days).

Figure 11 - Immunocontent of Toll-like receptor 4 (TLR4) in homogenates of isolated rat hearts submitted to ischemia and reperfusion after treatment with sulforaphane or vehicle for 3 days. GAPDH was used for normalization. Results are expressed as mean \pm S.D. with 4-5 animals per group (one representative Western blot experiment showing 3 bands for each experimental group). Comparisons between groups were made using the Student's $t$-test. $P=$ 0.19. CTL - vehicle treated rats; SFN - sulforaphane treated rats $(10 \mathrm{mg} / \mathrm{kg} /$ day for 3 days). 
Figure 12. Immunocontent of MyD88 in homogenates of isolated rat hearts submitted to ischemia and reperfusion after treatment with sulforaphane or vehicle for 3 days. GAPDH was used for normalization. Results are expressed as mean \pm S.D. with 4-5 animals per group (one representative Western blot experiment showing 3 bands for each experimental group). Comparisons between groups were made using the Student's $t$-test. $P=0.42$. CTL - vehicle treated rats; SFN - sulforaphane treated rats $(10 \mathrm{mg} / \mathrm{kg} /$ day for 3 days $)$.

Figure 13. Immunocontent of NF- $\mathrm{kB}$ in homogenates of isolated rat hearts submitted to ischemia and reperfusion after treatment with sulforaphane or vehicle for 3 days. $\alpha$-actinin was used for normalization. Results are expressed as mean \pm S.D. with 4-5 animals per group (one representative Western blot experiment showing 3 bands for each experimental group). Comparisons between groups were made using the Student's $t$-test. $P=0.67$. CTL - vehicle treated rats; SFN - sulforaphane treated rats $(10 \mathrm{mg} / \mathrm{kg} /$ day for 3 days $)$. 


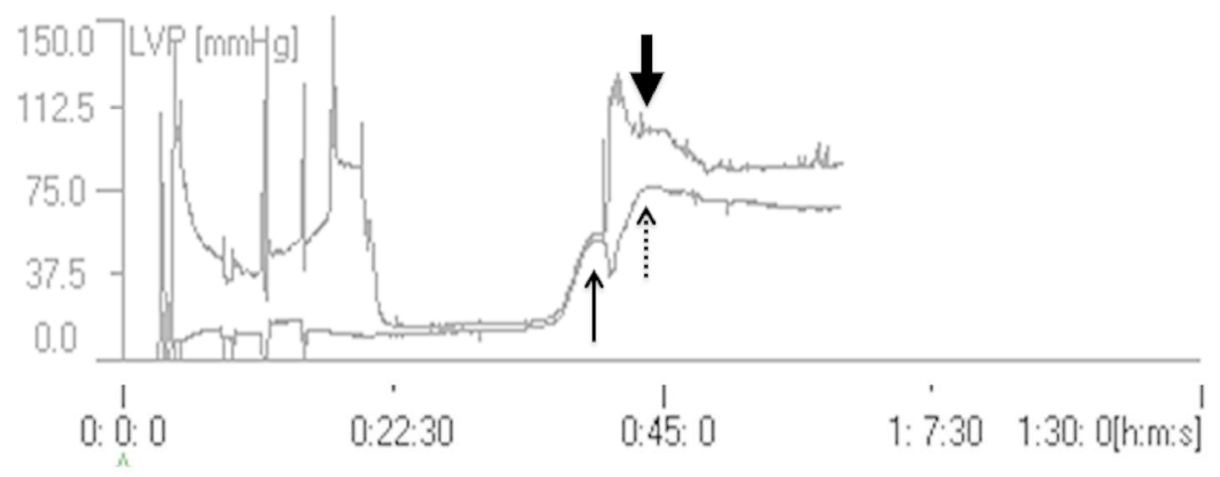

Figure 1

$191 \times 79 \mathrm{~mm}(300 \times 300$ DPI $)$ 
A

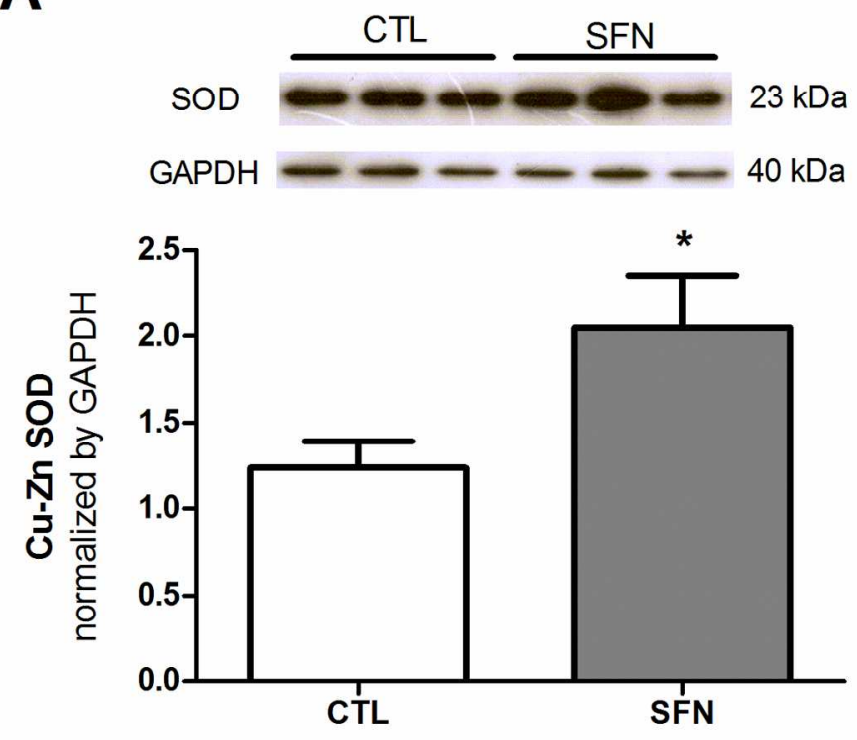

B

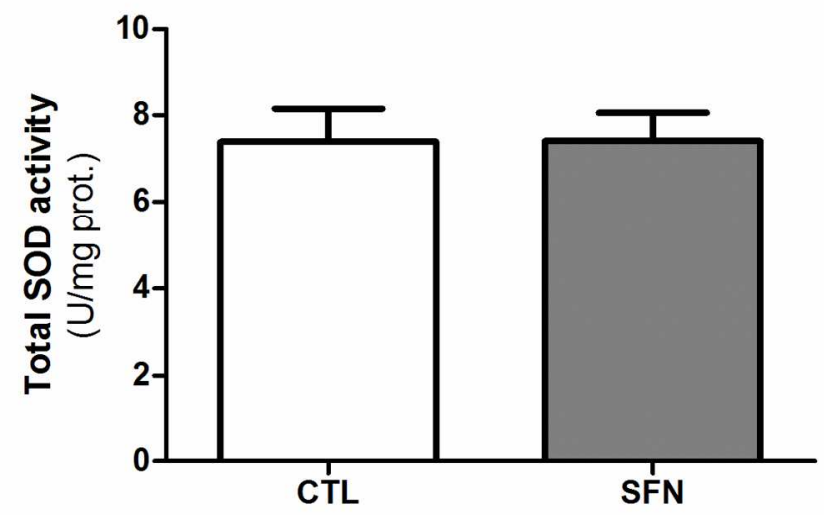

Figure 2

$117 \times 180 \mathrm{~mm}$ ( $300 \times 300$ DPI) 
A
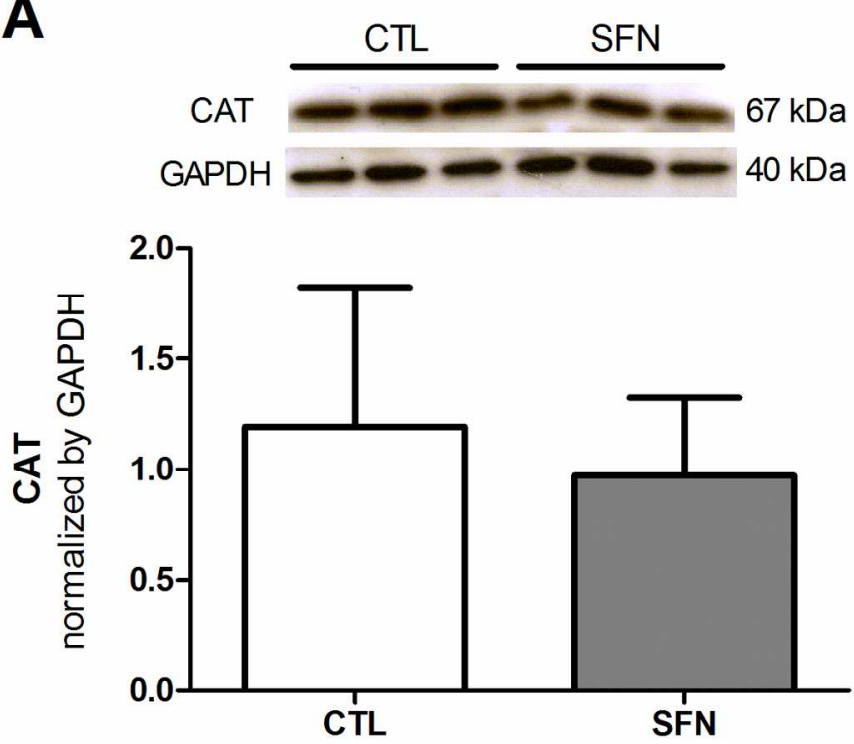

B

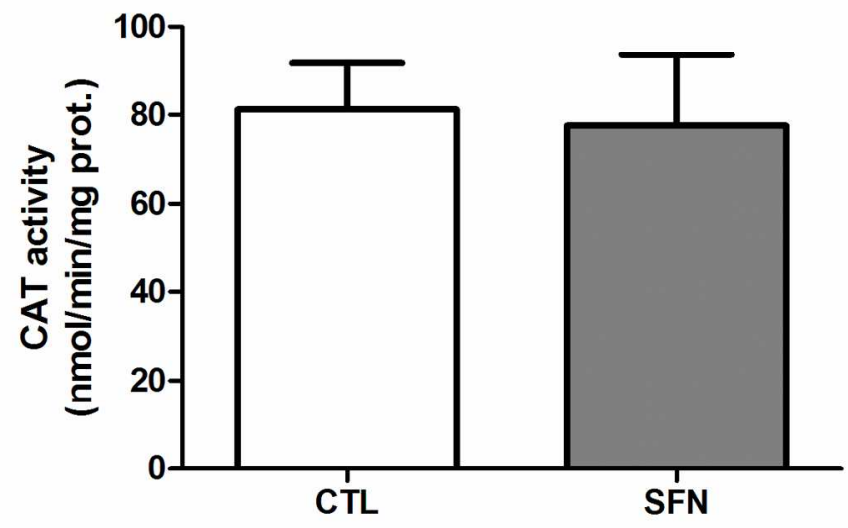

Figure 3

$118 \times 181 \mathrm{~mm}(300 \times 300 \mathrm{DPI})$ 
A
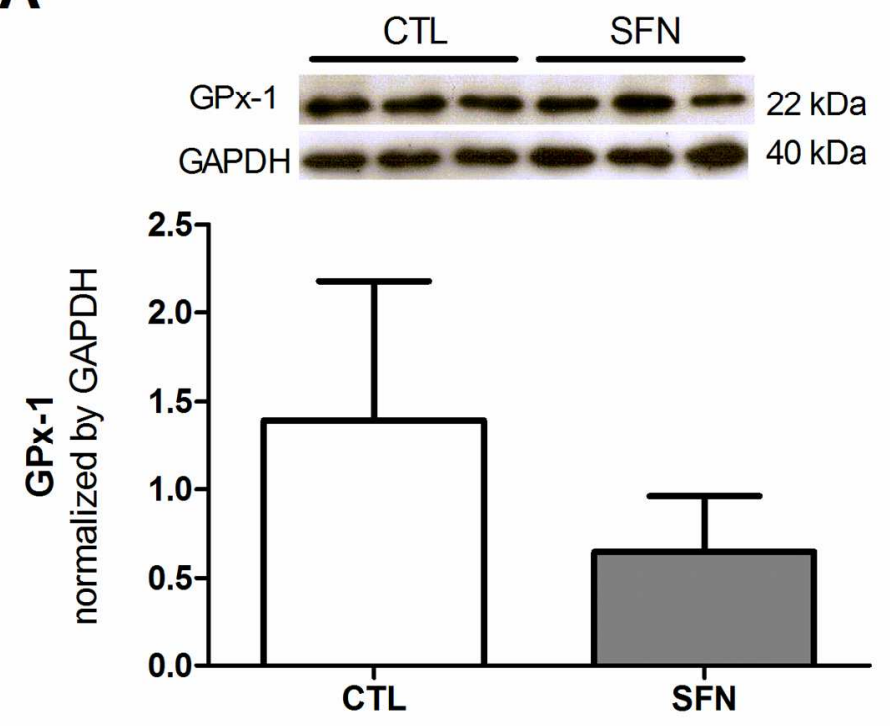

B

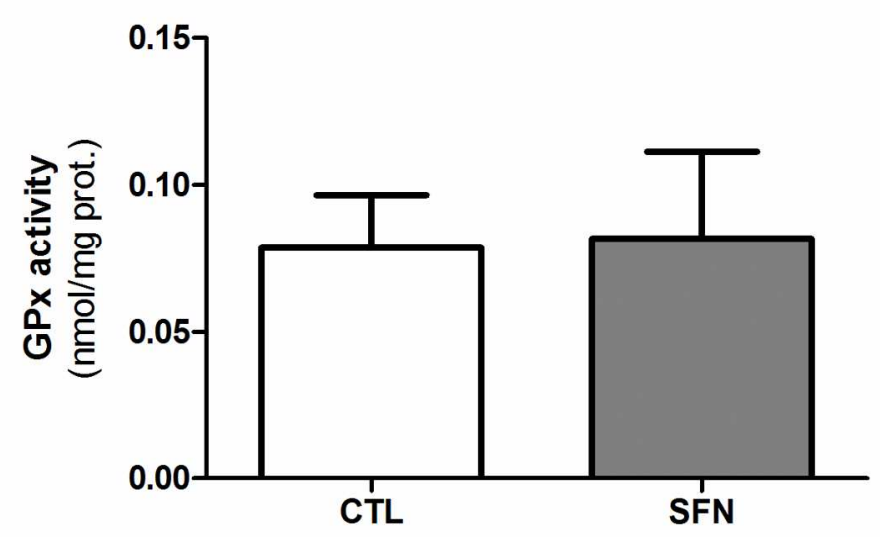

Figure 4

$123 \times 184 \mathrm{~mm}(300 \times 300 \mathrm{DPI})$ 


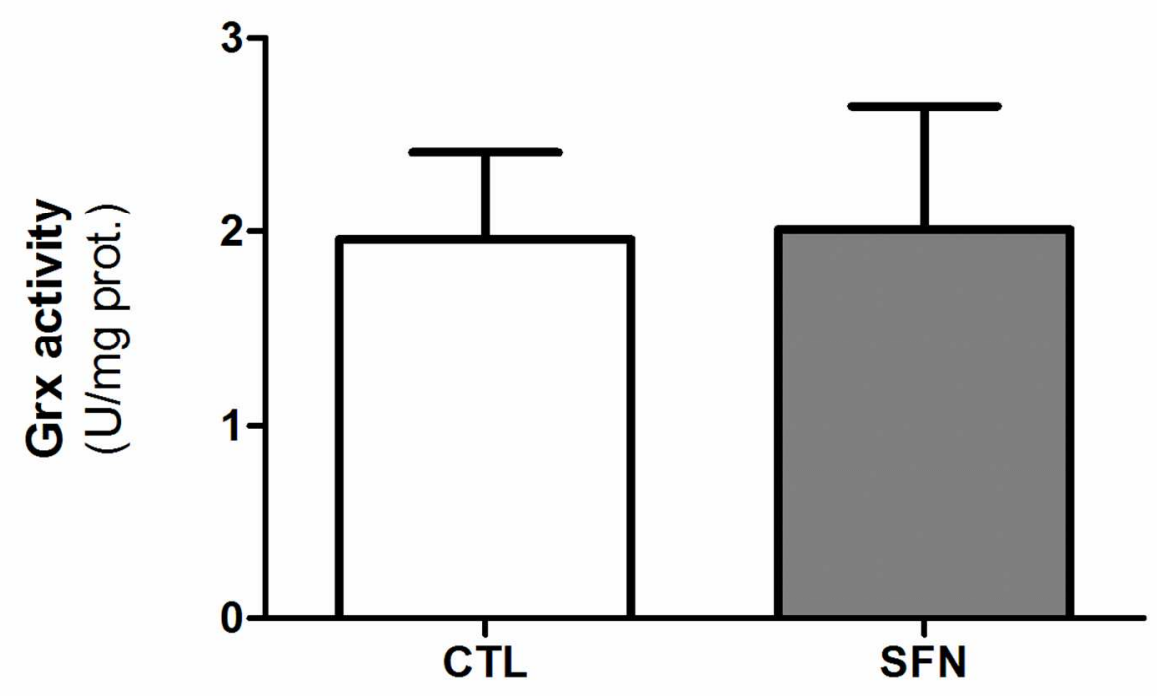

Figure 5

$113 \times 67 \mathrm{~mm}(300 \times 300 \mathrm{DPI})$ 


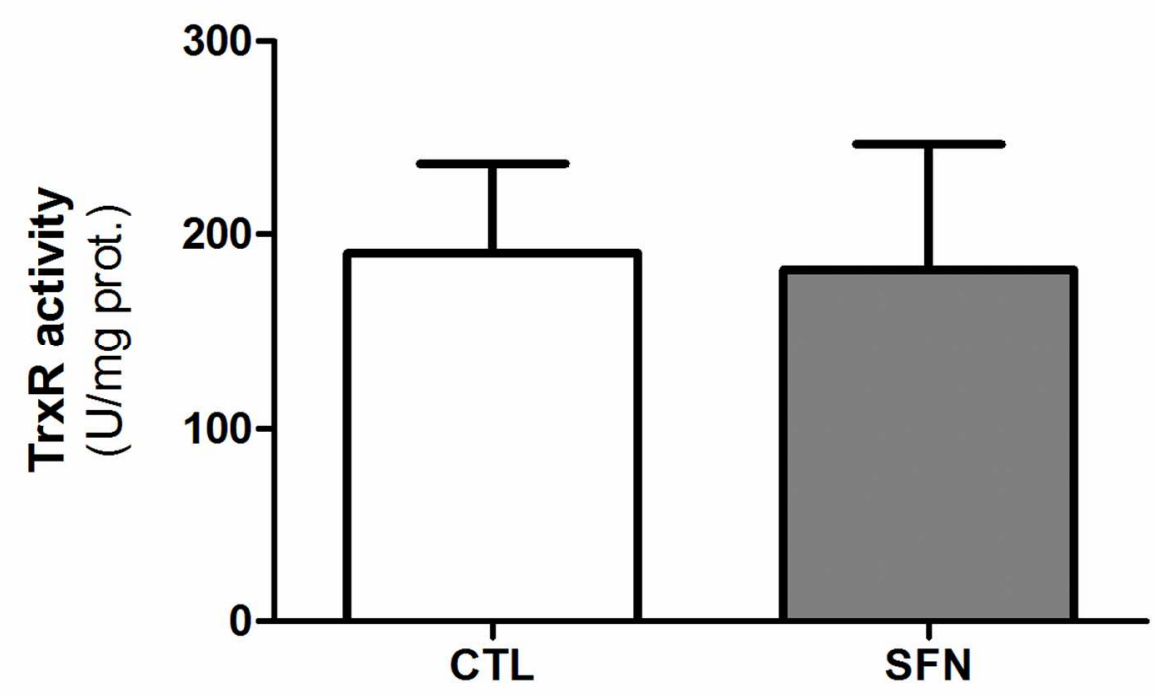

Figure 6

$113 \times 67 \mathrm{~mm}(300 \times 300 \mathrm{DPI})$ 


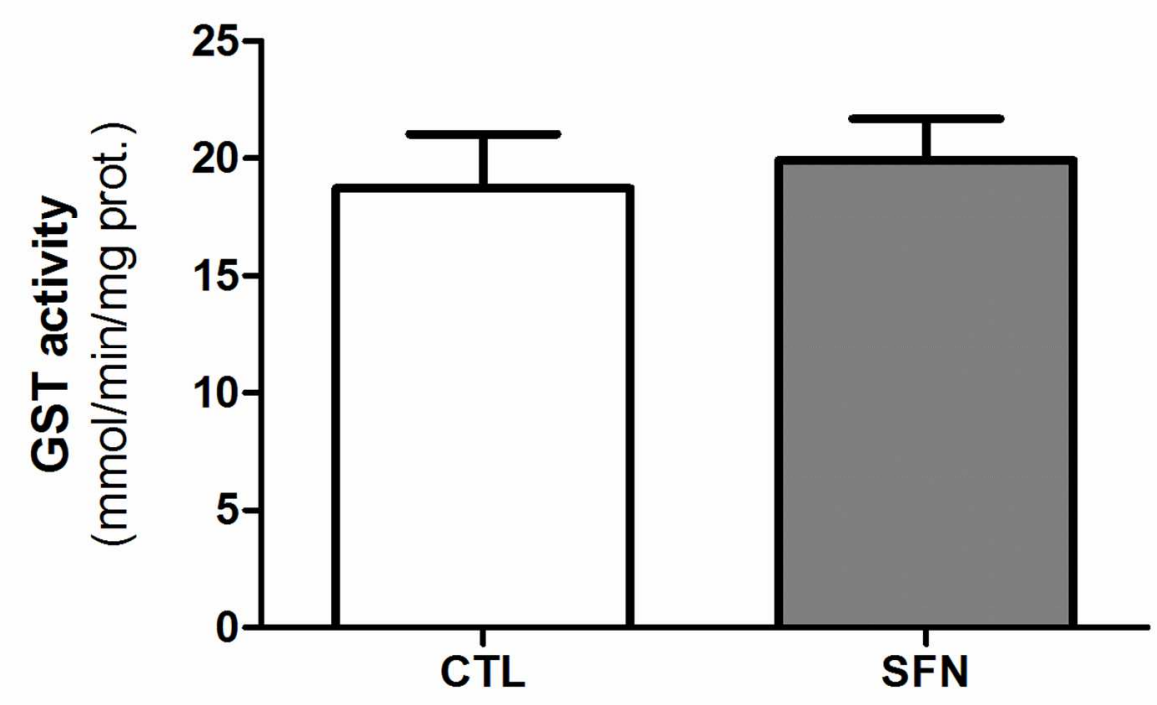

Figure 7

$112 \times 67 \mathrm{~mm}(300 \times 300 \mathrm{DPI})$ 


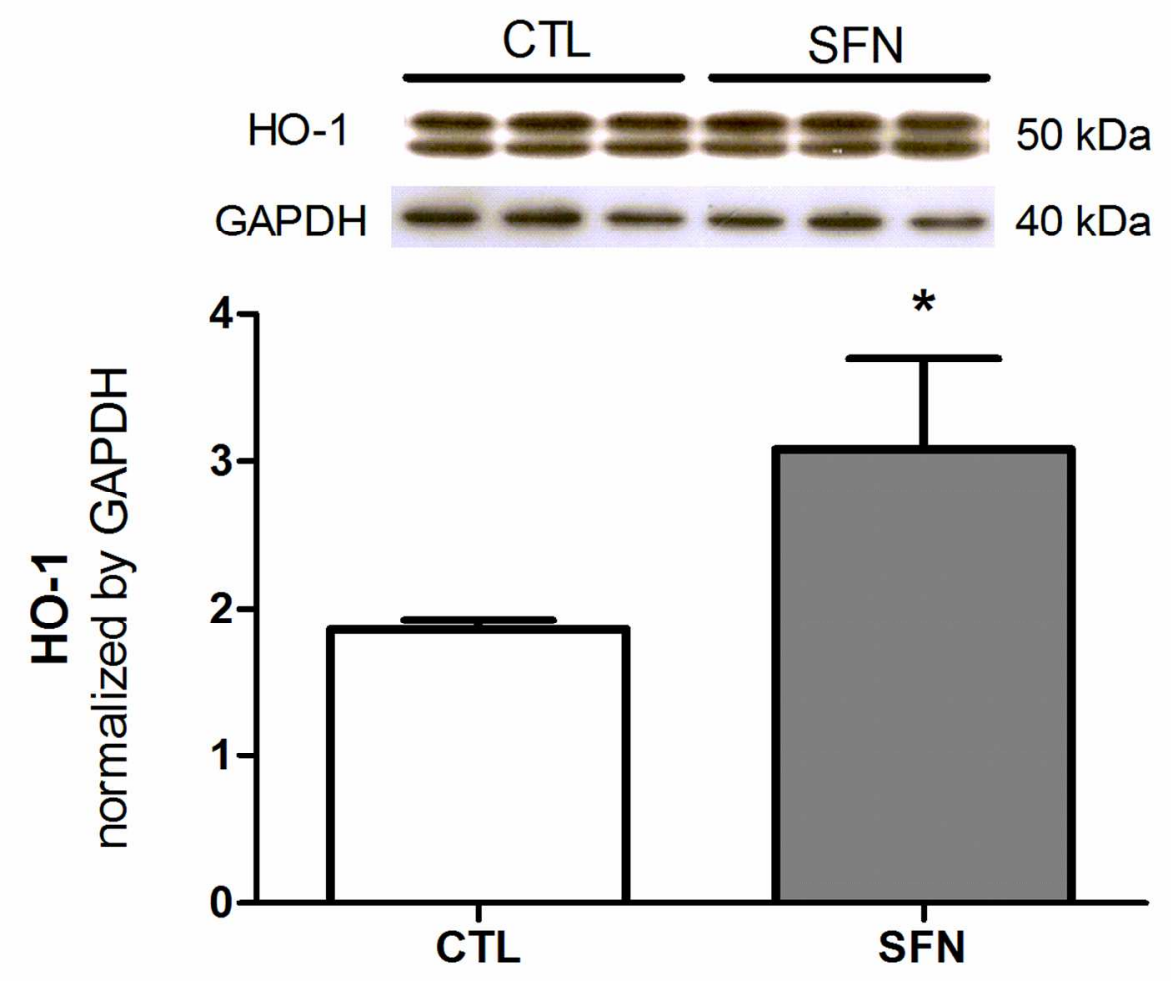

Figure 8

$111 \times 88 \mathrm{~mm}(300 \times 300 \mathrm{DPI})$ 


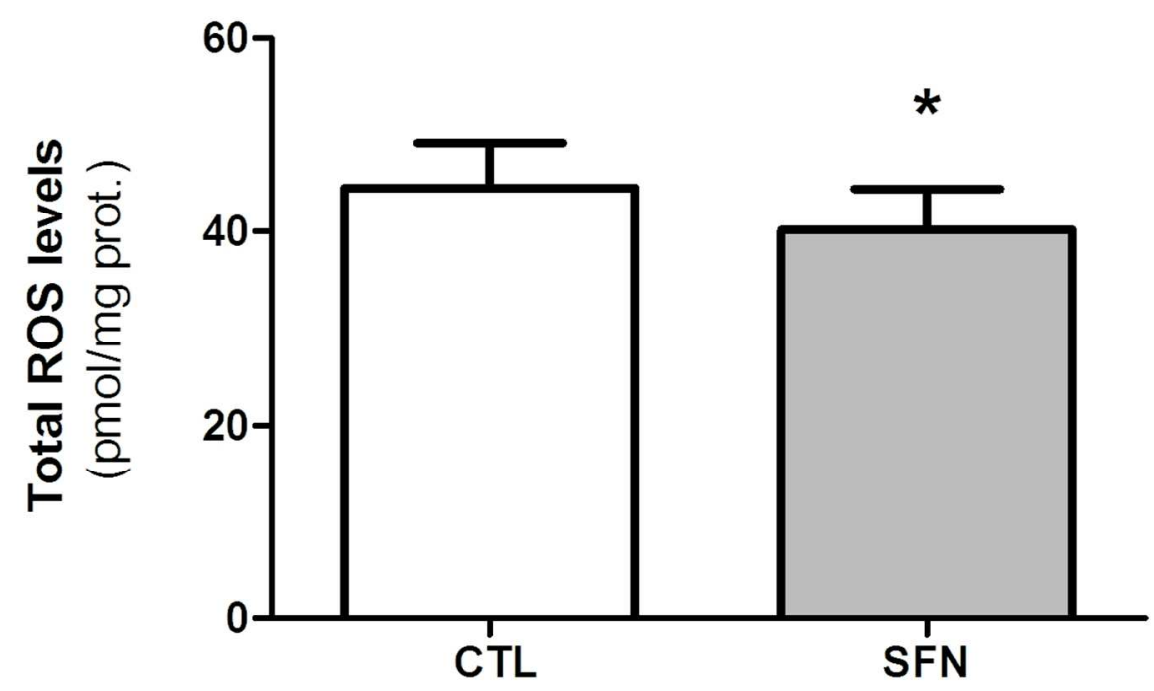

Figure 9

$113 \times 67 \mathrm{~mm}(300 \times 300 \mathrm{DPI})$ 


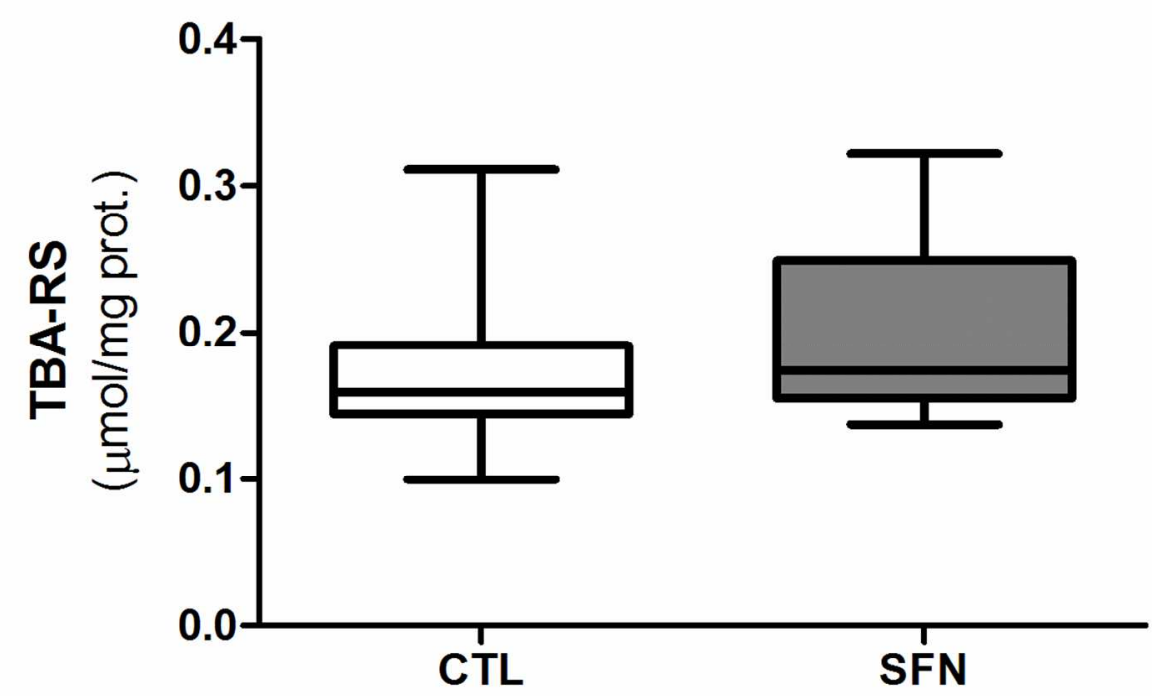

Figure 10

$112 \times 67 \mathrm{~mm}(300 \times 300$ DPI $)$ 


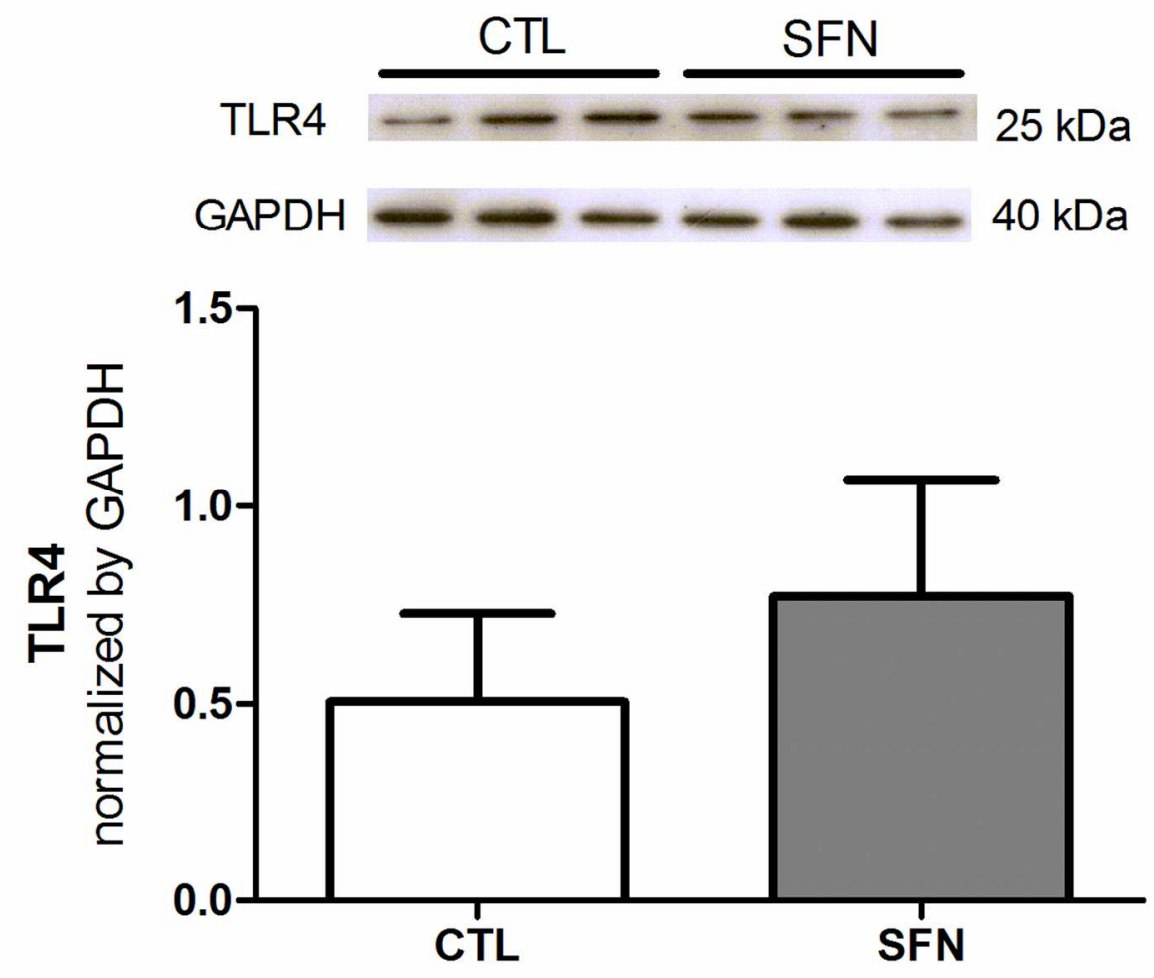

Figure 11

$110 \times 89 \mathrm{~mm}(300 \times 300 \mathrm{DPI})$ 


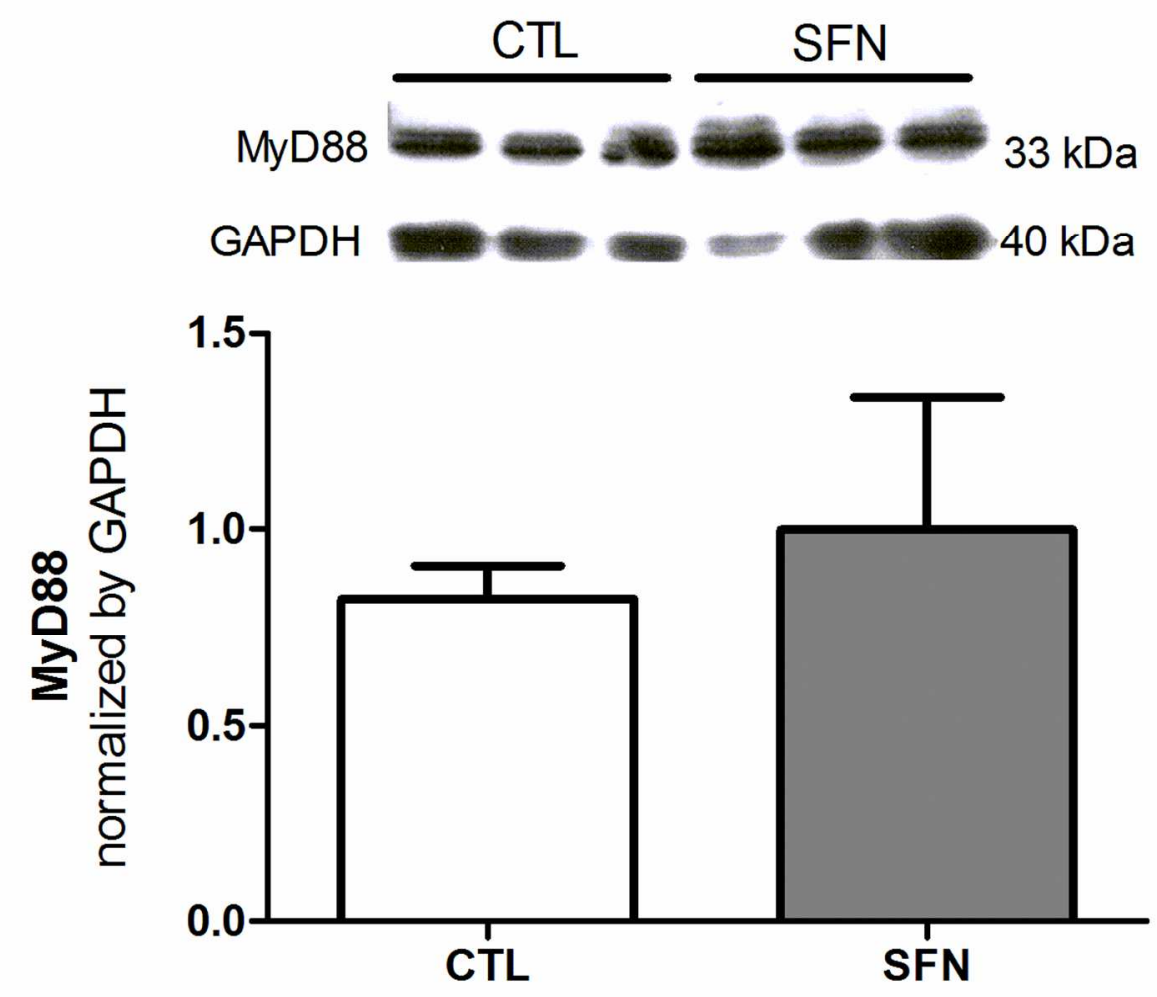

Figure 12

$112 \times 91 \mathrm{~mm}(300 \times 300$ DPI) 

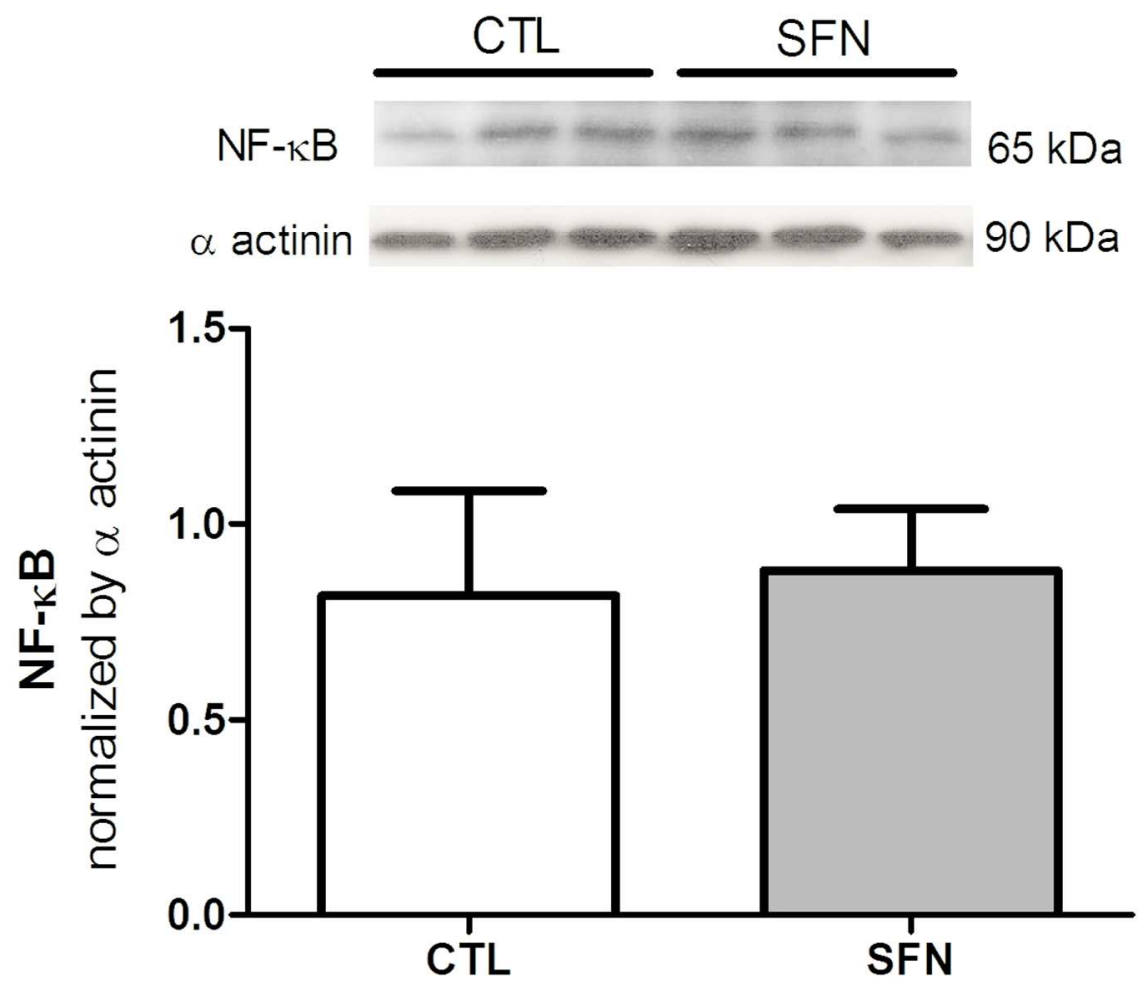

Figure 13

$112 \times 91 \mathrm{~mm}(300 \times 300 \mathrm{DPI})$ 